\title{
Design of Radio Over Plastic Optical Fibre for Broadband Indoor Access Network
}

\author{
*Isiyaku Yau, Suleiman M. Sani, Aliyu D. Usman, Abdoulie M. S. Tekanyi, Abdulmalik S. Yaro and Habeeb Bello \\ Department of Telecommunications Engineering, Ahmadu Bello University, Zaria, Nigeria \\ \{isiyakuyau | adusman | amtekanyi | asyaro\}@abu.edu.ng | \{smsani_2 I bellohabeebu\}@yahoo.com
}

\author{
ORIGINAL RESEARCH ARTICLE \\ Received: 07-OCT-2021; Reviewed: 13-NOV-2021; Accepted: 28-NOV-2021 \\ http://dx.doi.org/10.46792/fuoyejet.v6i4.703
}

\begin{abstract}
Indoor wireless traffic increases exponentially. Radio over fibre technology has been used to provide broadband services in the access network. Plastic Optical Fibre (POF) has been considered as a promising waveguide to be used as backhaul link for indoor access network. The Radio over Fibre (RoF) system uses an improved POF cable as a backhaul. A photonic antenna is developed by integrating a microstrip patch antenna with an opto-electronic converter. A standard inset fed microstrip patch antenna used for the wireless transmission and reception is designed using CST software tool. A RoF communication system based on the developed POF is designed and simulated using Optisystem software tool. The Bit Error Rate (BER) performance of the system in terms of Quality factor is evaluated. A maximum achievable POF cable length of $117 \mathrm{~m}$ for an On-Off Keying (OOK) transmission data rate of $1 \mathrm{Gbps}$ with an acceptable Quality factor of 7.0 is obtained. When the developed RoF system was used to transmit $10 \mathrm{Gbps}$ and $50 \mathrm{Gbps}$ data, the achievable cable lengths reduced to 80 $\mathrm{m}$ and $63 \mathrm{~m}$, respectively.
\end{abstract}

Keywords- Modal dispersion, photonic antenna, plastic Optical Fibre, RoF

\section{INTRODUCTION}

Wireless communication has become a widespread communication method for users because of its obvious mobility advantage. Indoor wireless traffic increases exponentially and is fast depleting the preferred radio spectrum resources. The increase in traffic is being driven by the need for broadband mobile services to smartphones, tablet computers, laptops, other devices as well, and by the interaction among multitudes of devices constituting the IoT. This wireless traffic is largely generated indoors (Koonen, 2018). Fig. 1 shows the global devices and connection growth.

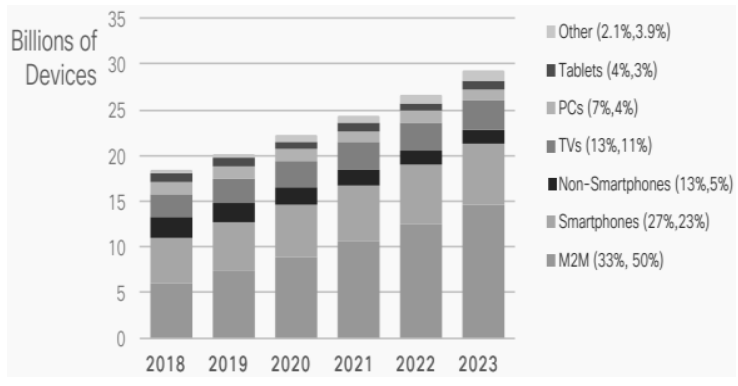

Fig. 1: Global Device and Connection Growth (Cisco Annual Internet Report, 2018)

According to Fig. 1, by the year 2023, the connected device comprising M2M, smartphones, TVs, PCs, and tablets would make up $50 \%, 23 \%, 11 \%, 4 \%$, and $3 \%$, respectively which add up to $91 \%$. The traffic produced by these devices of $91 \%$ are mostly generated indoor.

\footnotetext{
*Corresponding Author
}

Section B- ELECTRICAL/ COMPUTER ENGINEERING \& RELATED SCIENCES

Can be cited as:

Yau I., Sani S.M., Usman A.D., Tekanyi A.M.S., Yaro A.S., and Bello H. (2021) Design of Radio Over Plastic Optical Fibre for Broadband Indoor Access Network, FUOYE Journal of Engineering and Technology (FUOYEJET), 6(4), 358362. http://dx.doi.org/10.46792/fuoyejet.v6i4.703
The Radio over Fibre (RoF) technology is an effective solution for feeding broadband radio access points. RoF refers to the technique for transmitting radio frequency signals over optical fibre in order to provide wireless communication services. The system is also referred to as Fibre-Wireless (Fi-Wi) system. In Fi-Wi systems, the huge bandwidth of optical fibre is efficiently utilised to provide broadband wireless access by bringing the radio signal closer to the user and thus shortening the wireless channel. To realise a RoF Fi-Wi system, the optical carrier is modulated by RF signal(s) belonging to wireless access networks. Although there exit other forms of RF signal transmission over fibre for applications such as satellite base stations and cable television networks, the term RoF is exclusively used in the literature in relation to Fi-Wi communication systems. Fig. 2 illustrates a simple RoF structural architecture.

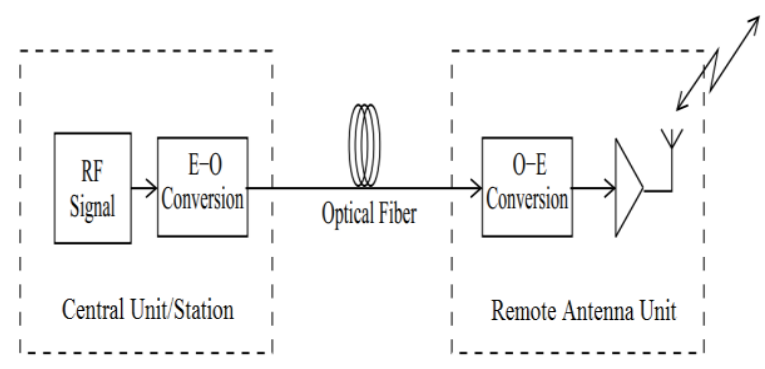

Fig. 2: Simple ROF Architecture (Albakay \& Nguyen, 2017)

RoF technology uses optical fibre links to distribute RF signals from a Central Station (CS) to Remote Antenna Units (RAUs). In narrowband wireless systems and WLANs, RF signal processing functionalities such as frequency up/down conversion, modulation technique, and multiplexing are carried out at each Base Station (BS) or Radio Access Point (RAP). The processed signals are immediately fed into the antenna modules of the RAPs. RoF allows for the centralization of the RF signal processing functions in one shared location (the CS). Optical fibre, which offers low signal attenuation, is then 
used to distribute the RF signals to the RAUs. The RAUs are made simpler because they need to perform only two functions, which are optoelectronic conversion and signal amplification. The centralization of RF signal processing functions facilitates equipment sharing, resource allocation, and simplified operation, and system maintenance (Albakay \& Nguyen, 2017).

The trend for the telecommunications network operators is to move closer to the home and even inside the residential vicinity to deploy fibre optics services because of its benefits in transmitting very large data. Future generations of wireless mobile networks would have to cater for the increased traffic demands of premises networks through the use of small cells. The Distributed Antenna System (DAS) may serve as a cost effective means to create hotspot points spread throughout the small cells and linked to a central station. The RoF has been a successful technology capable of fulfilling the requirements of small cell topology, particularly the DAS topology, for both indoor applications (Forni et al., 2016).

The remainder of the paper is organized as follows. In section 2, the related works are presented. Section 3, details the methodology. Numerical results and discussion are presented in section 4 . Section 5 gives the conclusion.

\section{RELATED WORKS}

Thomas et al, (2015) demonstrated experimentally the use of POF for digitized radio-over-fibre downlink. The digitized ROF was employed because of its capability in mitigating the effects of the non-linearity and fibre dispersion of the typical optical link between the base station and RAU. The effects limited both the attainable data rate as well as the fibre cable length. The signal transmission was based on Ethernet protocol at $5 \mathrm{GHz}$. The results of the experiment showed that the maximum achievable fibre cable length of the digital optical link is found to be $143 \mathrm{~m}$ at a speed up to $31.32 \mathrm{Mbps}$. However, the digitization of the ROF signal mitigated the fibre dispersion without improving the bandwidth length product of the fibre. Mittal et al., (2016) designed up to 100 Mbps POF link with LED and PIN photo-detector for indoor networking applications. The work presented a low cost, less complex solution for home networking applications utilising LED, POF and PIN photodiode to achieve up to $100 \mathrm{Mbps}, 100 \mathrm{~m}$, POF link with On-Off Keying (OOK) as the modulation scheme. Although going higher in order of PAM may improve the spectral efficiency of the system, it will however affect negatively on the SNR requirement of the system.

Albakay \& Nguyen (2017) presented a technique that mitigated the effect of modal dispersion of a standard POF. The work aimed to improve the data rate up to 1 Gbps. The modal dispersion was mitigated by reducing the effective numerical aperture of the fibre cable link. A spatial mode filter of a polycarbonate capillary tube was fabricated with an air gap in between the transceiver. The proposed technique was demonstrated experimentally on a $30 \mathrm{~m}$ link. A BER of less than $10-8$ at 1 Gbps was achieved. However, considerable power penalty was incurred which limited the achievable length of fibre link between transmitter and receiver.

\section{Methodology}

\subsection{OPTIMIZING THE POF BANDWIDTH}

For a POF having as the refractive indices of the core and cladding, respectively, the total modal dispersion per unit length is given by

$$
\Delta \tau_{\max }^{\prime}=\frac{n_{\text {core }}^{2}-n_{\text {cladding }}^{2}}{2 c_{o} n_{\text {core }}}
$$

The bandwidth-length product is improved by minimizing the modal dispersion per unit length of equation (1). This leads to the optimization problem of equation (2) subject to the constraints of equations (3) to (5).

$$
\min _{n} f(n) \equiv \frac{n_{\text {core }}^{2}-n_{\text {cladding }}^{2}}{2 c_{o} n_{\text {core }}}
$$

Subject to

$$
\begin{aligned}
& \eta_{c}=\left(1-R_{f}\right)\left(n_{\text {core }}^{2}-n_{\text {clad }}^{2}\right)=3 \% \\
& n_{\text {core }}, n_{\text {cladding }} \geq 1.3 \\
& n_{\text {core }}, n_{\text {cladding }} \leq 1.6
\end{aligned}
$$

where reflectivity, $\mathrm{Rf}$ is taken as $10 \%$ which is considered to be the worst-case scenario of the polymer. The choice of 3\% coupling efficiency is because LED is used as the optical source in order to have a cost-effective system. The refractive indices, $n$ of materials used for the manufacture of polymer optical fibre ranges from 1.3 to 1.6 (Bunge, et al. 2016).

The optimum values of the design variables, ncore and ncladding that minimize the objective function $f(n)$ in equation (2) are to be obtained, subject to the constraints in equations (3) to (5) being satisfied. To solve this problem, the fmincon function provided in MATLAB is used. The optimal design variables ncore and nclad are obtained as 1.4865 and 1.4756 , respectively. The minimum dispersion per unit length is $36.169 \mathrm{ps} / \mathrm{m}$.

\subsection{Design Of Microstrip PATCh ANTENNA}

The essential parameters for designing a microstrip patch antenna are the operating radio frequency (fr), the dielectric substrate height (h), and dielectric constant (cr). The selected operating radio frequency (antenna resonant frequency) is $5.8 \mathrm{GHz}$. The used dielectric substrate material is FR4-epoxy with a height of $1.6 \mathrm{~mm}$ and a dielectric constant of 4.4 .

The following steps are adopted as the design procedure for obtaining the remaining antenna parameters (Huang, 2021):

Step 1: Find an optimized width, $W$ for an efficient radiator as 


$$
W=\frac{\sqrt{2}}{2 f_{r} \sqrt{\varepsilon_{o} \mu_{o}\left(\varepsilon_{r}+1\right)}}
$$

Step 2: The effective permittivity, $\varepsilon_{\text {reff }}$ is calculated as:

$$
\varepsilon_{\text {reff }}=\frac{\varepsilon_{r}+1}{2}+\frac{\varepsilon_{r}-1}{2 \sqrt{1+12 d / W}}
$$

Step 3: Compute the extension of the length, $\Delta L$ as:

$$
\Delta L=\frac{0.0412 d\left(\varepsilon_{\text {reff }}+0.3\right)(W / d+0.264)}{\left(\varepsilon_{\text {reff }}-0.258\right)(W / d+0.8)}
$$

Step 4: The length, $L$ is determined as:

$$
L=\frac{1}{2 f_{r} \sqrt{\varepsilon_{r e f f} \varepsilon_{o} \mu_{o}}}-2 \Delta L
$$

Step 5: Calculate the ground plane dimensions $L g$, and $W g$ as:

$$
\begin{gathered}
L_{g}=L+6 h \\
W_{g}=W+6 h
\end{gathered}
$$

Step 6: Design the feed depth, $x_{0}$ as follows:

$$
x_{0}=\frac{L}{\pi} \cos ^{-1}\left(\frac{Z_{o}}{Z_{\text {in }}}\right)
$$

where $Z_{o}$ corresponds to the characteristic impedance $(50 \Omega)$ and $Z_{i n}$ is the input impedance given by:

$$
Z_{\text {in }}=90 \frac{\varepsilon_{r}^{2}}{\varepsilon_{r}-1}\left(\frac{L}{W}\right)^{2}
$$

After the essential parameters $f_{r}, \varepsilon_{r}$, and $h$ are specified, the patch width, $W$ and length, $L$ are obtained using equations (6) through (13). The microstrip patch antenna is designed and optimised using the CST MWS. Table 1 Shows the optimal microstrip patch antenna geometry parameters obtained.

\begin{tabular}{ll} 
Table 1. Microstrip Patch Antenna Geometry Parameters \\
$\begin{array}{l}\text { Microstrip antenna } \\
\text { parameters }\end{array}$ & $\begin{array}{l}\text { Parameter } \\
\text { Value }\end{array}$ \\
\hline Material used & FR4 \\
Dielectric constant $(\varepsilon r)$ & 4.3 \\
Antenna height $(h)$ & $1.6 \mathrm{~mm}$ \\
$\begin{array}{l}\text { Rectangular patch } \\
\text { dimensions }(W)\end{array}$ & $15.8 \mathrm{~mm}$ \\
Rectangular patch & \\
dimensions $(L)$ & $11.5 \mathrm{~mm}$ \\
Substrate width, $\left(W_{8}\right)$ & $43 \mathrm{~mm}$ \\
Substrate length, $\left(L_{8}\right)$ & $45 \mathrm{~mm}$ \\
Inset feed depth, $\left(x_{0}\right)$ & $3 \mathrm{~mm}$
\end{tabular}

The antenna is simulated in order to obtain the sparameter. The s-parameter is exported in a Touchstone file format which contains all the required information for the microstrip patch antenna such as antenna return loss, gain, operating frequency and the S-parameter. The file is fed into the Optisystem software tool in order to develop the overall system model. Fig. 3 shows a 2D view of the developed microstrip patch antenna.

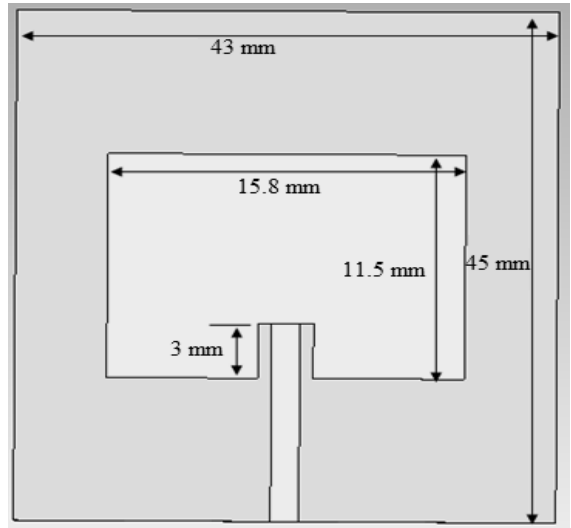

Fig. 3: Developed Microstrip Patch Antenna

\subsection{Developed Rof System Model}

Fig. 4 illustrates the system model of the hybrid radiooptical wireless communication system. It consists of a digital signal transmitter, optical link components, identical microstrip patch antennas separated by a radio wireless link and a digital signal receiver.

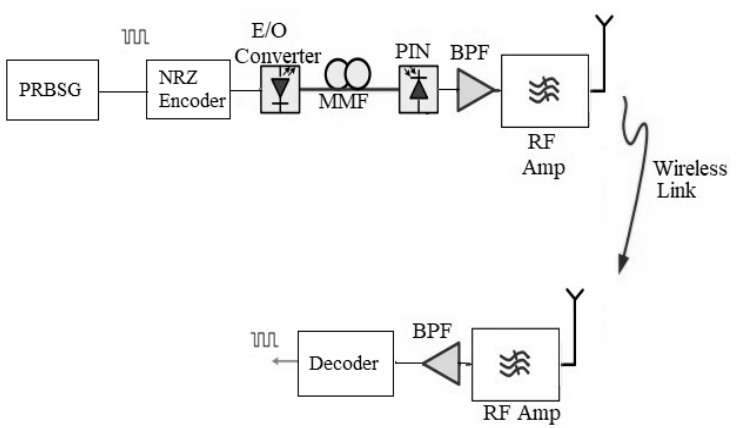

Fig. 4: Developed RoF System Model

First, the blocks are built using Optisystem communication software tool (see appendix 3 ) and for the wireless part, Touchstone file format specifications are used for implementing the patch antenna scattering parameters in the two port component S2P. The main variable parameters are the fibre length and the free space path between the microstrip patch antennas. The developed POF length varies from $10 \mathrm{~m}$ to $150 \mathrm{~m}$. The distance between the antennas is set at a maximum distance of $10 \mathrm{~m}$ for femtocells which is equivalent to 102.3 dB. The RoF system parameters are given in Table 2. 
Table 2. System Parameters

\begin{tabular}{ll}
\hline Parameter & Value \\
\hline Modulation scheme & OOK \\
Carrier Frequency & $5.8 \mathrm{GHz}$ \\
Signal bandwidth & $125 \mathrm{MHz}$ \\
Bit rate & $1,10,50 \mathrm{Gbps}$ \\
Optical wavelength & $650 \mathrm{~nm}$ \\
Optical launch power & $6 \mathrm{~dB}$ \\
POF size & $200 / 250 \mu \mathrm{m}$ \\
POF core refractive Index & 1.487 \\
POF cladding refractive Index & 1.467 \\
Refractive index contrast & 0.737 \\
Numerical aperture & 0.180 \\
POF attenuation & $1.588 \mathrm{~dB} / \mathrm{m}$ \\
POF length & $10-150 \mathrm{~m}$ \\
Antenna directivity & $8.33 \mathrm{dBi}$ \\
Antenna radiation efficiency & $-3.45 \mathrm{~dB}$ \\
Antenna gain & $8.34 \mathrm{dBi}$ \\
Antenna beam width & $64.2 \mathrm{o}$ \\
Wireless pathloss & $102.3 \mathrm{~dB}$ \\
\hline
\end{tabular}

\section{RESULTS AND DISCUSSION}

\subsection{Antenna Performance Evaluation}

The relationship between the antenna return loss, |S11| in $\mathrm{dB}$ with the frequency in $\mathrm{GHz}$ is illustrated in Fig. 5. The antenna is designed to operate in the $5.8 \mathrm{GHz}$ ISM band (5.725-5.85 GHz). To ensure good antenna performance, the return loss should be lower than -9.5 $\mathrm{dB}$ (Khalily et al., 2018). The minimum return loss value obtained at $5.8 \mathrm{GHz}$ is $-38.02 \mathrm{~dB}$. This implies that more than $99 \%$ of the incident power is transferred into the antenna with very title reflection.

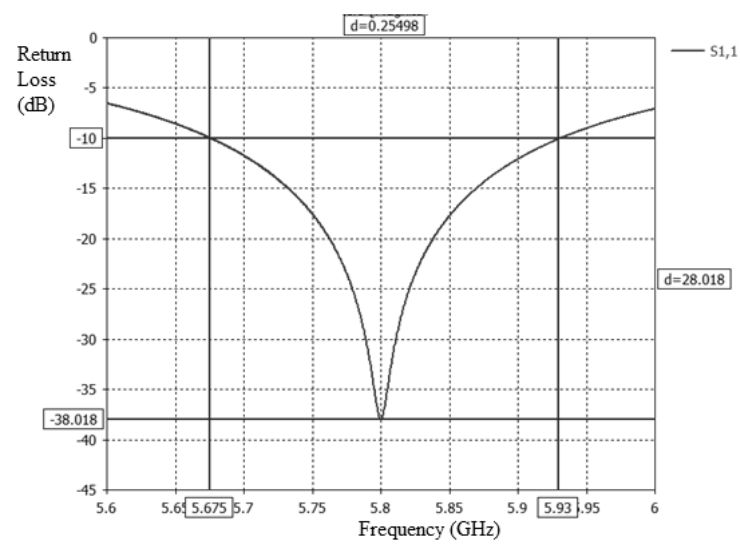

Fig. 5: Antenna Return Loss vs Radio Frequency

The bandwidth of the antenna is the frequency range measured at $-10 \mathrm{~dB}$ return loss which is measured to be about $255 \mathrm{MHz}$. Thus, the return loss plot shown in Fig 2.3 indicates good resonance at the designed frequency of $5.8 \mathrm{GHz}$. Fig. 6 shows the 3D plot of the directivity of the antenna. The directivity and the radiation efficiency of the antenna are $8.33 \mathrm{dBi}$ and $-3.45 \mathrm{~dB}$ respectively.

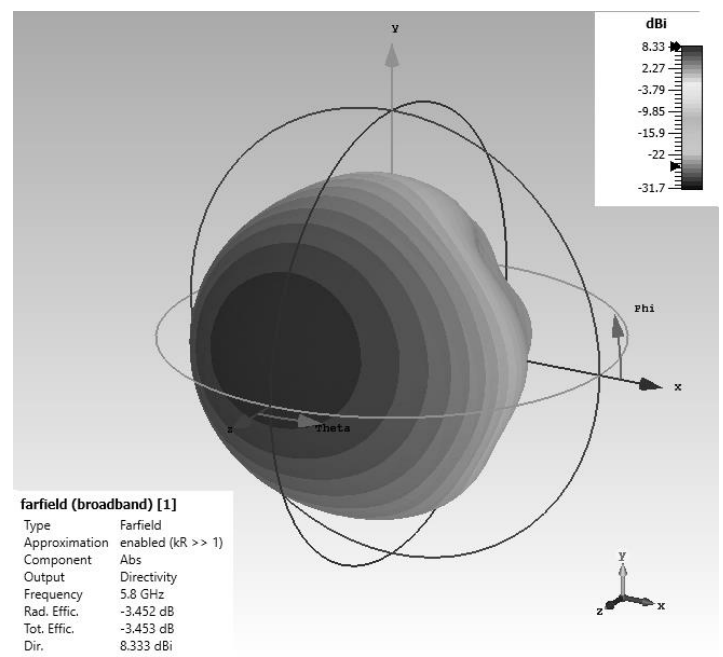

Fig. 6: 3D Plot of Directivity

Fig. 7 depicts the radiation pattern of the antenna. The maximum gain of the antenna is $8.34 \mathrm{dBi}$ at $5.8 \mathrm{GHz}$. The half power points are observed at 64.2 degrees as shown in Fig 6.

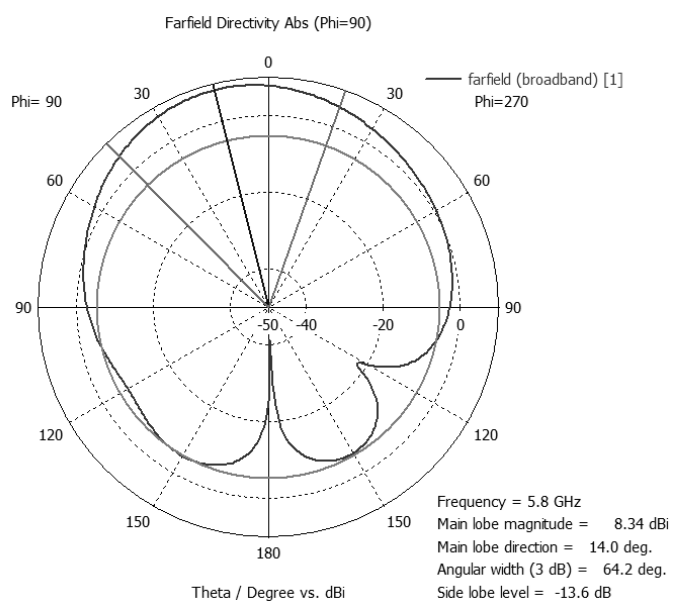

Fig. 7: Antenna Radiation Pattern

\subsection{RoF System Performance Evaluation}

The BER is the ultimate determinant of the quality of a communication system. It is difficult to measure, especially for simulations. The quality factor provides a convenient measure of overall system quality. For an acceptable digital transmission in an optical communication system, the quality factor should be greater than or equal to 7.0 which is corresponding to BER of less or equal to 10-12 (ITU-T-REC-G.989).

Fig. 8 shows the variation of the quality factor with the optical fibre length for various bit rates. The quality factor decreases with the increase in the optical fibre cable length, irrespective of the transmission speed. 


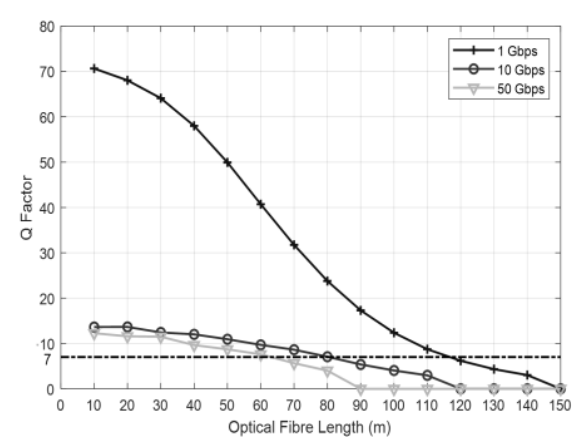

Fig. 8: Quality factor versus Optical Fibre Length

At an optical fibre length of $10 \mathrm{~m}$ and a bit rate of $1 \mathrm{Gbps}$, the quality factor is 70.7. For the same bit rate of $1 \mathrm{Gbps}$ and cable length of $110 \mathrm{~m}$, the quality factor drops gradually to 8.7 . It is found by extrapolation that the cable length which gives a quality factor of 7.0 is about $117 \mathrm{~m}$ beyond which the Quality factor decreases exponentially for a bit rate of $1 \mathrm{Gbps}$. This is due to the dispersive nature and attenuation of the POF cable which increase with increase in length of the cable. Thus, the maximum achievable cable length for the developed POF suitable for data communication using On-Off Keying (OOK) modulation is $117 \mathrm{~m}$. Similarly, for $10 \mathrm{Gbps}$ and $50 \mathrm{Gbps}$ transmission, the maximum achievable cable lengths are $80 \mathrm{~m}$ and $63 \mathrm{~m}$ respectively.

For the purpose of comparison, Mittal et al., (2016) was able to design a low cost POF communication link up to $100 \mathrm{~m}$ cable length and a data rate of $100 \mathrm{Mbps}$. Also a mode filtering technique for dispersion mitigation in POF was presented by Albakay and Nguyen, (2017) in which 1 Gbps transmission for a cable length of $30 \mathrm{~m}$ was achieved. This work therefore produces improvements in terms of both cable length and data rates as compared to the work of Mittal et al., (2016). When compared with the work of Albakay and Nguyen (2017), for the same transmission data rate of $1 \mathrm{Gbps}$, this work was able to extend the length of fibre link from $30 \mathrm{~m}$ to $117 \mathrm{~m}$. This represent about $300 \%$ improvement in terms of the POF cable length. Extending the reach of POF length is one of significant contribution of this work. Fig. 9 illustrates the variation of Signal-to-Noise Ratio (SNR) with optical fibre cable length under different transmission speeds. It is observed that the received SNR at the user terminal decreases linearly with an increase in the fibre cable length regardless of the transmission data rate.

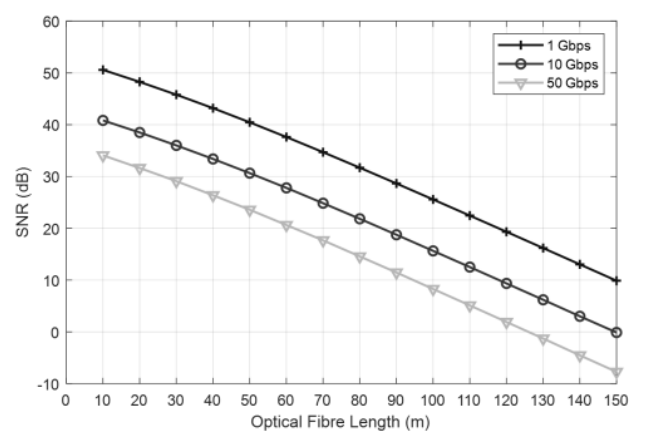

Fig. 9: Variation of SNR with Optical Fibre Cable Length
For a fixed optical fibre cable length, higher data rate results in lower SNR. For example, at $100 \mathrm{~m}$ cable length, the received SNR are $25.6 \mathrm{~dB}, 15.6 \mathrm{~dB}$ and $8.3 \mathrm{~dB}$ for data rates of $1 \mathrm{Gbps}, 10 \mathrm{Gbps}$, and $50 \mathrm{Gbps}$, respectively. The SNR values obtained at the maximum achievable POF cable lengths for transmission data rates of $1 \mathrm{Gbps}$, Gbps, and $\mathrm{Gbps}$ are $20.3 \mathrm{~dB}, 21.8 \mathrm{~dB}$, and $19.752 \mathrm{~dB}$, respectively. The acceptable SNR level is application dependent. For wireless access networks, signals with an SNR value of 20 $\mathrm{dB}$ or more are recommended for data transmission. Thus, SNR values obtained at the maximum achievable cable length are considered acceptable.

\section{Conclusion}

A radio over fibre communication system based on Plastic Optical Fibre (POF) for broadband indoor access network is developed. The bandwidth of the access backhaul link has been improved by minimizing the modal dispersion of the cable. The modal dispersion of the POF cable is reduced by finding optimal core and cladding materials for the optical fibre. A photonic antenna is developed by integrating a microstrip patch antenna with an optoelectronic converter. A standard inset fed microstrip patch antenna used for the wireless transmission and reception is designed using CST software tool. A RoF communication system based on the developed POF is designed and simulated using Optisystem software tool. The BER performance of the system in terms of qualityfactor is evaluated. An achievable optical fibre cable length of $117 \mathrm{~m}$ is obtained with acceptable quality factor of 7.0 for a bit rate of $1 \mathrm{Gbps}$. Further works could be done to enhance the achievable sum capacity of the developed RoF system by exploiting higher modulation techniques such as quadrature amplitude modulation (QAM) and Carrierless Amplitude and Phase (CAP) modulation.

\section{REFERENCES}

Albakay, N. A., \& Nguyen, L. (2017). Achieving 1 Gbps Over StepIndex Plastic Optical Fibre Using Spatial Mode Air-Gap Filter. IEEE Photonics Technology Letters, 29(8), 655-658.

Bunge, C. A., Beckers, M., \& Gries, T. (Eds.). (2016). Polymer Optical Fibres: Fibre Types, Materials, Fabrication, Characterisation and Applications. Woodhead Publishing.

Forni, F., Shi, Y., van den Boom, H., Tangdiongga, E., \& Koonen, T. (2016). Multiband LTE-A and 4-PAM signals over large-core plastic fibres for in-home networks. IEEE Photonics Technology Letters, 28(20), 2281-2284.

Huang, Y. (2021). Antennas: from theory to practice. John Wiley \& Sons.

Khalily, M., Tafazolli, R., Xiao, P., \& Kishk, A. A. (2018). Broadband $\mathrm{mm}$-wave microstrip array antenna with improved radiation characteristics for different 5G applications. IEEE Transactions on Antennas and Propagation, 66(9), 4641-4647.

Koonen, T. (2018). Indoor optical wireless systems: technology, trends, and applications. Journal of Lightwave Technology, 36(8), 1459-1467.

Mittal, N., Shah, M., \& John, J. (2016). A low cost short haul plastic optical fibre link for home networking applications. In Recent Trends in Electronics, Information \& Communication Technology, IEEE International Conference, 2112-2116.

Thomas, V. A., Liu, D., El-Hajjar, M., \& Hanzo, L. (2015). Experimental demonstration of plastic optical fibre-based digitised radio over fibre downlink. Electronics Letters, 51(21), 1679-1681. 